\title{
Brazilian physiotherapy in the global reality
}

$O^{1}$ ince 1969, when physiotherapy was regulated as a profession, we have witnessed an incredible scientific and technical development of our class. From a profession that was born with a "rehabilitationist" vision and with an object of work that is still not very well defined, in these 45 years, we have been able to consolidate Brazilian physiotherapy as a consistent and independent profession, as well as undeniably relevant to our country's public health.

Of course, we still have some problems to be solved. However, the level of projection to which we got is much higher than many of our professionals know. We are respected worldwide, and our profession and professionals are seen as a model.

We are one of the few countries in the world in which physiotherapy has the autonomy to receive patients at first contact. We produce quality scientific research and, in number of professionals, we are the nation with the most physiotherapists in the world, with approximately 170,000 professionals.

We are political leaders of the Latin American region, since the chairmanship of both the Latin American Confederation of Physical Therapy and Kinesiology (CLAFK) and the South American Region of the World Confederation for Physical Therapy (WCPT-SAR) is conducted by a Brazilian representative, which projects the visibility of our physiotherapy even further.
Our participation in international scientific events is always relevant. In the latest World Congress of Physical Therapy, held in the Netherlands in 2011, Brazil was the second country in number of participants and studies presented, and it is also worth mentioning that a Brazilian has won the award for best presentation.

In 2014, we will have the opportunity to show the world the strength and quality of Brazilian physiotherapy. And we will show all this right here, in our own country, since we will carry out, in the city of São Paulo, from October 27th to 29th, the XIX LATIN AMERICAN CONGRESS OF PHYSICAL THERAPY AND KINESIOLOGY and the IV WCPTSAR CONGRESS, under the responsibility of the Brazilian Physiotherapists Association (AFB). On October 25th and 26th, also in the city of São Paulo, we will hold the $V$ CONFERENCE OF LATIN AMERICAN ACADEMICS (ELA).

We welcome all physiotherapists to attend these events. In addition to sharing experiences and knowledge with professionals from various countries, we will show, together, the quality of our physiotherapy, and how valuable Brazilian physiotherapists are.

Prof. Reginaldo Antolin Bonatti, Ph.D Chairman of CLAFK Chairman of WCPT - SAR Chairman CREFITO-3 